Sehr geehrte Frau Kollegin, sehr geehrter Herr Kollege, gemäß $\S 14$ Abs. 2, 4 und 8 der Satzung laden wir hiermit alle Mitglieder des Freien Verbandes Deutscher Zahnärzte e.V. in BadenWürttemberg ganz herzlich ein zur

\section{Landesversammlung Baden-Württemberg}

Termin: Samstag, den 09. Juli 2016, $9.30 \mathrm{Uhr}$, Ort: DENTAURUM GmbH \& Co. KG, Turnstraße 31, 75228

Ispringen

\section{Tagesordnung:}

1. Begrüßung

2. Gastvortrag: „Und führe mich nicht in Versuchung - Korruption im Gesundheitswesen“

Referenten: Prof. Dr. iur. Thomas Ratajczak, SindelfingenThomas Hochstein, Erster Staatsanwalt, Staatsanwaltschaft Stuttgart

3. Eröffnung der Sitzung gem. $\$ 1$ der Geschäftsordnung

4. Regularien

5. Fragestunde

(Die Fragen dürfen sich nicht auf Punkte der Tagesordnung beziehen und müssen gemäß $₫ 5$ der Geschäftsordnung mindestens 5 Tage vor der Sitzung der Landesversammlung in der Landesgeschäftsstelle, Albstadtweg 9, 70567 Stuttgart, schriftlich eingegangen sein.)

6. Bericht des Landesvorsitzenden

7. Diskussion

8. Geschäftsbericht

9. Bericht der Kassenprüfer

10. Entlastung des Landesvorstandes

11. AnträgeAnträge, die die Tagesordnung verändern, sind zwei Wochen vor der Landesversammlung schriftlich beim Landesvorstand über die Landesgeschäftsstelle einzureichen.

12. Verschiedenes

Die Landesversammlung ist für Mitglieder des Freien Verbandes öffentlich. Rede- und stimmberechtigt sind nur die Delegierten.

Mit freundlichen Grüßen

Freier Verband Deutscher Zahnärzte e.V. Landesverband Baden-Württemberg Dr. Joachim Härer, Landesvorsitzender

\section{Hier steht eine Anzeige.}

Springer 